\title{
Harro Zimmermann, Günter Grass und die Deutschen. Eine Entwirrung. Essay
}

\section{Anne-Marie Corbin}

\section{OpenEdition}

Journals

Édition électronique

URL : http://journals.openedition.org/ifha/9032

DOI : 10.4000/ifha.9032

ISSN : 2198-8943

Éditeur

IFRA - Institut franco-allemand (sciences historiques et sociales)

Référence électronique

Anne-Marie Corbin, «Harro Zimmermann, Günter Grass und die Deutschen. Eine Entwirrung. Essay », Revue de l'IFHA [En ligne], Date de recension, mis en ligne le 24 avril 2018, consulté le 24 septembre 2020. URL : http://journals.openedition.org/ifha/9032 ; DOI : https://doi.org/10.4000/ifha.9032

Ce document a été généré automatiquement le 24 septembre 2020

(CIFHA 


\section{Harro Zimmermann, Günter Grass und die Deutschen. Eine Entwirrung. Essay}

Anne-Marie Corbin

\section{RÉFÉRENCE}

Harro Zimmermann, Günter Grass und die Deutschen. Eine Entwirrung. Essay, Göttingen: Wallstein, 2017, 362 p., 29,90€ 
Au début de sa réflexion sur Günter Grass et les Allemands, Harro Zimmermann introduit le petit Oskar Matzerath personnage principal du premier volet de la trilogie de Danzig, Le Tambour. A la fin des années 1950, au moment où la démocratie peine à s'instaurer en Allemagne, Oskar accuse les Allemands et jugent ceux qui ont accepté la guerre et la Shoah. Une quarantaine d'années plus tard, c'est le sommet de la consécration de Grass avec l'attribution du Prix Nobel. Artiste souvent controversé, écrivain célébré et citoyen en appelant à la responsabilité et à la prise de conscience, mais ne faisant pas toute la lumière sur sa propre biographie, Günter Grass est l'objet de mainte controverse, inhérente à une personnalité qui se complaît dans une certaine provocation et prône

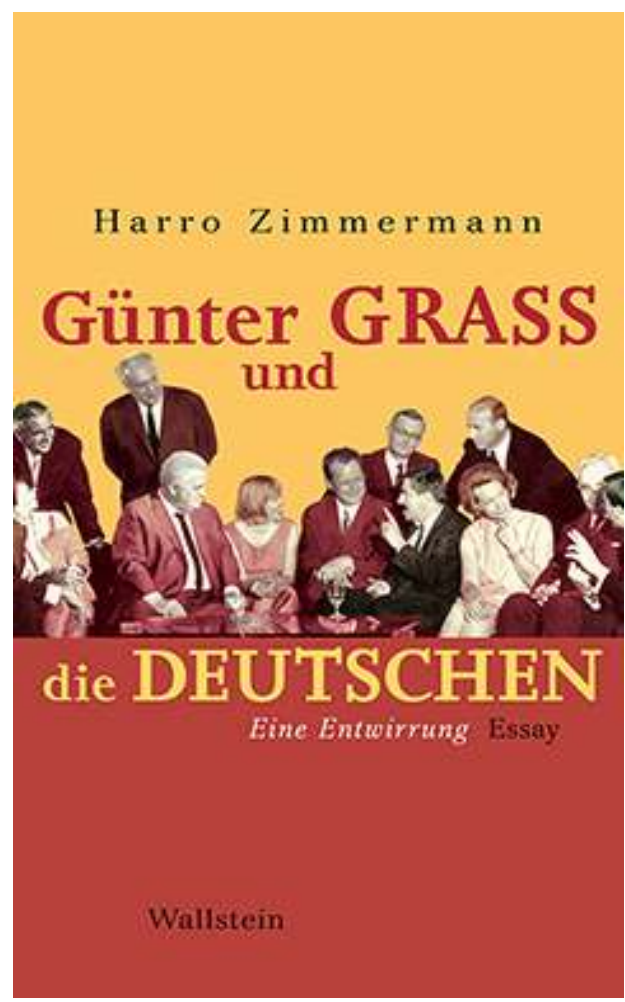
constamment la résistance.

Fêté et primé par le Groupe 1947 dès 1958

(surnommé « der Hai im Sardinentümpel deutscher Gegenwartsliteratur ", « le requin dans la mare aux sardines de la littérature contemporaine allemande »), Grass devient ce qu'il ne cessera jamais d'être -l'empêcheur de tourner en rond dans une Allemagne peu encline à effectuer sur le passé nazi un travail de retour qui se fait attendre pratiquement jusqu'en 1968. Pourtant, en 1963, le Procès Auschwitz se déroule à Francfort et met en accusation le personnel du camp.

Harro Zimmermann analyse l'œuvre de Grass et sa réception par la critique littéraire, les intellectuels et quelques philosophes comme Adorno. Le sentiment se fait jour que Grass ne recule jamais devant la tentation de briser des tabous, qu'il lutte avec la littérature contre l'hypocrisie des pouvoirs en place - la CDU d'Adenauer à l'époque qui pervertit les esprits. Dans la trilogie romanesque de Grass, on note un processus de réflexion sur les rapports entre Allemands et Juifs après guerre, assumé grâce à la construction des personnages et leurs destins individuels. Pourtant Grass va être parfois accusé à tord d'antisémitisme par ses détracteurs, comme l'écrivain Yoram Kaniuk en 1991. Roman après roman, les « monstres littéraires » qu'il se plaît à créer ne trouvent pas non plus grâce auprès des autorités de la RDA le traitant «d'antimilitariste nihiliste ». Grass ne se conforme pas à l'injonction d'Adorno de ne plus écrire de poèmes après Auschwitz : les siens prônent la déconstruction idéologique au plus fort de la Guerre froide.

Le public allemand a vite pris conscience de l'existence de cet écrivain dérangeant, au plus tard au début des années 1960. C'est un moment où les invectives des critiques pleuvent - de Friedrich Sieburg à Hans Egon Holthusen - contre ce "phénomène de l'industrie culturelle" et la position qu'il occupe dorénavant grâce à son nonconformisme, situé par certains à droite, par d'autres à gauche. Grass réagit aux événements qui secouent le monde, la guerre d'Algérie, la crise de Cuba et, en 
Allemagne, l'affaire du Spiegel où Franz Josef Strauß est couvert par l'administration d'Adenauer. En 1965, Grass obtient le Prix Büchner. C'est aussi l'époque de la guerre au Vietnam et la première grande manifestation à Berlin en 1966. On est au cœur de l'engagement politique de Grass aux côtés du SPD, puis pour soutenir la campagne électorale de Willy Brandt, dont il approuve pleinement le geste symbolique devant le monument du ghetto de Varsovie, et la politique à l'Est. Cependant, à partir de 1973, il critique le gouvernement et il faut attendre 1999 pour que Schröder et Fischer trouvent davantage grâce à ses yeux.

Jusqu'à la moitié de l'ouvrage, cet aperçu des priorités politiques de Grass laisse de côté ses opinions par rapport au mouvement étudiant, à la RDA et à l'unification allemande. C'est pourquoi Harro Zimmermann se voit contraint à plusieurs reprises de revenir aux années 1960 pour, chaque fois, évoquer ces autres problématiques. Le lecteur ne peut s'empêcher de se demander si une autre organisation du plan de l'ouvrage n'aurait pas permis d'éviter cet écueil. Il semble que Harro Zimmermann soit plus à l'aise dans la présentation des ouvrages de Grass et des critiques littéraires qui les accompagnent. C'est ce que l'on peut constater pour l'évocation de ses derniers romans et surtout des remous provoqués par les tardives révélations de Grass sur son enrôlement précoce à la Waffen-SS.

Notons également que le principe des citations et de leurs références en notes est pour le moins troublant. Dans le corps du texte, Harro Zimmermann ne recourt pas toujours aux guillemets pour indiquer la prise de parole par Grass ou autre. Parfois, la citation est mise en italique, parfois entre guillemets, avec ou sans renvoi à un bloc de références situées à la fin de l'ouvrage et qu'il faut enfin comparer avec la bibliographie finale. C'est mettre le lecteur à trop rude épreuve...

\section{INDEX}

Index chronologique : Époque contemporaine

Mots-clés : Histoire de la culture, Histoire des idées 